\title{
MAGEA6 Positive
}

National Cancer Institute

\section{Source}

National Cancer Institute. MAGEA6 Positive. NCI Thesaurus. Code C135574.

An indication that melanoma-associated antigen 6 expression has been detected in a sample. 